\title{
Pharmacokinetics, Safety, and Intraocular Pressure-Lowering Profile of Omidenepag Isopropyl, a Selective, Nonprostaglandin, Prostanoid EP2 Receptor Agonist, in Healthy Japanese and Caucasian Volunteers (Phase I Study)
}

\author{
Makoto Aihara, ${ }^{1}$ Fenghe Lu, ${ }^{2}$ Hisashi Kawata, ${ }^{3}$ Yuki Tanaka, ${ }^{3}$ Kenzo Yamamura, ${ }^{4}$ \\ Noriko Odani-Kawabata, ${ }^{2,3}$ and Naveed K. Shams ${ }^{2,3}$
}

\begin{abstract}
Purpose: Omidenepag isopropyl (OMDI) is a prodrug of OMD, a selective, nonprostaglandin, prostanoid EP2 receptor agonist. This phase I study aimed to investigate the pharmacokinetic properties, safety, and intraocular pressure (IOP)-lowering efficacy of OMDI.

Methods: Fourteen healthy male volunteers (7 Japanese and 7 Caucasian) 20-35 years of age received 1 drop of OMDI $0.0025 \%$ at 9:00 $\mathrm{h}$ in both eyes for 7 days. Blood samples were taken predose and up to $8 \mathrm{~h}$ postdose on days 1,3 , and 7 . The plasma concentration of OMD was determined using high-performance liquid chromatography-tandem mass spectrometry. Pharmacokinetic parameters measured included the maximum plasma concentration $\left(C_{\max }\right)$ and the half-life $\left(t_{1 / 2}\right)$ of OMD. IOP, adverse events (AEs), ophthalmic examinations, vital signs, and laboratory values were assessed.

Results: $C_{\max }$ for all subjects was reached after 10-15 min and decreased with a $t_{1 / 2}$ of $\sim 30 \mathrm{~min}$. Ad hoc statistical analyses found significant differences in some pharmacokinetic parameters between Japanese and Caucasian subjects, likely due to differences in body weight. These differences reduced over 7 days of dosing and were not thought to be clinically meaningful. There was no OMD accumulation after 7 days of repeated dosing. Mean IOP was reduced by $\sim 4-5 \mathrm{mmHg}$ between baseline and $2 \mathrm{~h}$ postdose, remaining stable from day 3 onward. All AEs were mild and considered treatment related.

Conclusions: Pharmacokinetic parameters of OMD were similar between Japanese and Caucasian subjects. There was no accumulation of OMD after 7 days of dosing. OMDI was well tolerated and demonstrated clinically significant IOP reductions.
\end{abstract}

Keywords: glaucoma, omidenepag isopropyl, EP2 receptor agonist, pharmacokinetics, intraocular pressure, phase I

\section{Introduction}

G LAUCOMA IS A major ocular disorder that, if left untreated, can lead to irreversible blindness as a result of retinal ganglion cell death and optic nerve damage. ${ }^{1}$ The main strategy to prevent glaucoma progression is to reduce intraocular pressure (IOP). ${ }^{2}$ There are several classes of
IOP-reducing medications, including prostanoid FP receptor agonists (FP agonists, such as prostaglandin analogs), betablockers, carbonic anhydrase inhibitors (CAIs), adrenergic agonists, rho kinase inhibitors, and cholinergics. ${ }^{2,3}$

FP agonists, such as latanoprost, bimatoprost, tafluprost, and travoprost, are the most common medication class used to lower IOP. FP agonists are efficacious, usually well tolerated

\footnotetext{
${ }^{1}$ Department of Ophthalmology, University of Tokyo, Bunkyo-ku, Japan.

${ }^{2}$ Santen, Inc., Emeryville, California.

${ }^{3}$ Santen Pharmaceutical Co., Ltd., Osaka, Japan.

${ }^{4}$ Santen Pharmaceutical Co., Ltd., Ikoma, Japan.
}

(C) Makoto Aihara et al. 2019; Published by Mary Ann Liebert, Inc. This Open Access article is distributed under the terms of the Creative Commons Attribution Noncommercial License (http://creativecommons.org/licenses/by-nc/4.0/) which permits any noncommercial use, distribution, and reproduction in any medium, provided the original author(s) and the source are cited. 
with few systemic side effects, and need to be taken only once daily, which promotes good treatment adherence. ${ }^{2,4}$ However, it has been shown that $\sim 40 \%$ of patients treated with FP agonists require adjunctive treatment to sufficiently reduce their IOP; $\sim 9 \%$ of patients require 3 medications to achieve a target IOP of $\leq 24 \mathrm{mmHg}$ and a minimum $20 \%$ reduction in IOP. ${ }^{5,6}$

One study found that the percentage of patients who required adjunctive therapy was $35.0 \%$ for those on travoprost, $51.3 \%$ for those on bimatoprost, and $37.3 \%$ for those on latanoprost ${ }^{7}$; the median time to initiation of adjunctive therapy was 113,83 , and 101 days, respectively. ${ }^{7}$

Additionally, studies have shown that some patients have little or no response to FP agonists. ${ }^{8-10}$ However, reported rates of nonresponse are varied, potentially because of differences in patient population, definition of nonresponse, and duration of clinical study.

In a retrospective study in Japanese patients $(n=57)$, latanoprost nonresponse, defined as a $\leq 10 \%$ IOP reduction rate, was reported in $28.1 \%$ of patients at month $3 .{ }^{8}$ Furthermore, in a prospective randomized study of predominantly Caucasian patients $(n=111 / 136 ; 82 \%)$, latanoprost nonresponse, defined as an IOP reduction of $<15 \%$ from baseline at every measurement during the day $(8: 00,12: 00$, and 16:00 h), was reported in $51.5 \%$ of the 125 patients who were treated with latanoprost and completed the 6-month study. ${ }^{10}$ Of those treated with latanoprost, 30 patients $(22 \%)$ had previously been treated with FP agonists, including latanoprost. ${ }^{11}$

However, in a multicenter prospective study involving patients who had not previously been exposed to prostaglandins and in which latanoprost nonresponse was defined as an IOP reduction of $<15 \%$ from baseline (average of 6 measurements from 8:00 to $18: 00 \mathrm{~h}$ ), only 14 of $340(4.1 \%)$ patients were described as nonresponders after 1 month of latanoprost treatment. ${ }^{9}$

Therefore, although FP agonists have good IOP-lowering efficacy, additional treatments with new mechanisms of action are still required. Omidenepag isopropyl (OMDI), an ocular hypotensive agent with a novel mechanism of action, ${ }^{12}$ was approved by the Japanese regulatory authority in September 2018 for the treatment of glaucoma and ocular hypotension. OMDI is hydrolyzed in the eye during corneal penetration to its active metabolite OMD, a selective, nonprostaglandin, prostanoid EP2 agonist. ${ }^{4} \mathrm{~A}$ study in ocular hypertensive monkeys demonstrated that OMDI lowers IOP by increasing the outflow of aqueous humor from both the uveoscleral pathway (176\% increase compared with vehicle treatment; $P=0.033$ ) and the conventional outflow pathway $(71 \%$ increase; $P=0.028) .{ }^{12}$

This differs from the findings of aqueous humor dynamics studies of FP agonists, which demonstrate that aqueous humor outflow is increased predominantly through the uveoscleral pathway. ${ }^{13-15}$ A study of travoprost $0.004 \%$ in monkeys demonstrated that the increase in uveoscleral outflow was significant in normotensive eyes $(P=0.02)$, but that there was no effect on aqueous flow or outflow facility. ${ }^{13}$ Similarly, a study investigating the mechanism of action of latanoprost $0.005 \%$ in cynomolgus monkeys with glaucoma concluded that the uveoscleral outflow was increased but that there was no effect on outflow facility or aqueous humor flow rate. ${ }^{15}$

This phase I, open-label, single-arm study was designed to evaluate the plasma pharmacokinetics, safety, tolerability, and IOP-lowering efficacy of topically administered OMDI in healthy Japanese and Caucasian subjects.

\section{Methods}

\section{Materials}

OMDI was manufactured by Ube Industries Ltd. (Yamaguchi, Japan). The structure of OMDI has been described previously. ${ }^{4}$

\section{Study design}

The study was conducted at one study center in Kagoshima, Japan. The study was approved by the CPC Clinical Trial Hospital's Institutional Review Board before study initiation. The study was conducted in accordance with the ministerial ordinance on Good Clinical Practice and with ethical principles based on the Declaration of Helsinki.

Written informed consent was obtained from each subject. As this is a phase I study, no power calculation was performed. Seven subjects per group (Japanese and Caucasian) were enrolled to meet the sample size requirements for pharmacokinetics and safety assessment in a phase I study and to allow for study dropouts. Subjects were administered 1 drop of OMDI ophthalmic solution $0.0025 \%$ in both eyes once a day at 9:00 $\mathrm{h}$ for 7 days. This dose was selected based on the safety and efficacy findings from a phase II dosefinding study. ${ }^{16}$

The key inclusion criteria were age 20-35 years; healthy male volunteer; central corneal thickness (CCT) $\geq 480$ and $\leq 600 \mu \mathrm{m}$ in each eye; and Japanese or Caucasian ethnicity (Japanese subjects were defined as having been born in Japan to parents who were both Japanese, and Caucasian subjects were defined as having been born outside of Japan to parents who were both Caucasian). The key exclusion criteria were a corrected visual acuity of $<1.0$ in either eye when measured with the Snellen visual acuity chart; body weight $\leq 80 \%$ or $\geq 120 \%$ of the standard body weight expected; a history of current ocular or systemic diseases; drug or alcohol dependency; and excessive exercise.

\section{Pharmacokinetics}

Blood samples for pharmacokinetic analysis were collected from each subject and placed in a blood-collection tube containing heparin sodium at the following time points: predose, and $5 \mathrm{~min}, 15 \mathrm{~min}, 30 \mathrm{~min}, 1 \mathrm{~h}, 2 \mathrm{~h}, 4 \mathrm{~h}$, and $8 \mathrm{~h}$ after OMDI administration on days 1,3 , and 7 . At each time point, 2 samples were taken to provide a primary and a back-up sample. After collection, the blood sample was immediately centrifuged at $4^{\circ} \mathrm{C}$ and $3,000 \mathrm{rpm}$ for $10 \mathrm{~min}$ to obtain the plasma fraction. Plasma samples were stored frozen (at $-80^{\circ} \mathrm{C}$ at the clinical site and then at less than $-65^{\circ} \mathrm{C}$ at the test facility) until analyzed.

The plasma concentration of OMD was determined by validated high-performance liquid chromatography-tandem mass spectrometry assays using the deuterated form of $\mathrm{OMD}$ as an internal standard. The lower limit of quantification for the plasma concentration of OMD was $1.00 \mathrm{pg} / \mathrm{mL}$. In-study validation at 3 nominal concentrations demonstrated assay accuracy ranging from $88 \%$ to $109 \%$ for plasma concentrations. A retrospective $t$-test was performed to assess differences in the pharmacokinetic parameters between the Japanese and Caucasian subject populations; differences were considered significant if the $P$-value was $<0.05$. 


\section{IOP measurement}

IOP was measured during the screening period, 1 day before instillation (at 9:00, 10:00, 11:00, 13:00, 17:00, and 21:00 h), immediately before instillation (9:00 h), and at 1, 2, 4,8 , and $12 \mathrm{~h}$ postdose on days $1-7$, and at 9:00 h on day 8 . IOP was measured in triplicate in both eyes using an FT-1000 noncontact ophthalmotonometer (Tomey Corporation, Nagoya, Aichi, Japan), and the mean IOP value was recorded.

\section{Safety}

The occurrence and severity of adverse events (AEs), including abnormal laboratory values, were recorded from day 1 to 8 . The causality of the AE was adjudicated by the investigator. If a causal relationship to the medication was reasonable, the event was defined as an adverse drug reaction. Iritis was prespecified as an important risk of treatment.

In addition to AEs, other safety variables that were recorded included ophthalmic examinations, vital signs, and laboratory values. Ophthalmic examinations included slit-lamp biomicroscopy, refractometry, pachymetry, anterior segment photography, and ophthalmoscopy, in addition to measurements of visual acuity, pupil diameter, and aqueous flare. The vital signs measured were blood pressure, pulse rate, and 12-lead electrocardiography. Blood and urine samples were collected on days 1 and 8 to determine laboratory values such as aspartate aminotransferase (AST) and alanine aminotransferase (ALT) levels, in addition to other hematological, blood biochemistry, serological, and urinalysis test values. CCT was measured using an ultrasound pachymeter SP-100 (Tomey Corporation) at 8:00 h on days $1-7$ and at 9:00 h on day 8 .

\section{Calculation of pharmacokinetic parameters}

Pharmacokinetic parameters were calculated for each subject using Phoenix WinNonlin Professional version 6.4 (Certara, L.P., Princeton, NJ). These parameters were area under the curve computed to $8 \mathrm{~h}\left(\mathrm{AUC}_{0-8 \mathrm{~h}}\right), \mathrm{AUC}$ extrapolated to infinity $\left(\mathrm{AUC}_{\mathrm{inf}}\right)$, maximum plasma concentration $\left(C_{\max }\right)$, time to reach maximum plasma concentration $\left(T_{\max }\right)$, and halflife $\left(t_{1 / 2}\right)$ of OMD.

\section{Results}

\section{Demographics}

In total, 14 healthy male subjects enrolled in and completed the study (7 Japanese and 7 Caucasian). Baseline demographics and clinical characteristics are shown in Table 1.

\section{Pharmacokinetics}

The plasma concentration profiles of OMD on days 1,3 , and 7 after dosing of OMDI ophthalmic solution $0.0025 \%$ in both eyes at 9:00 h are shown in Fig. 1. Table 2 shows the pharmacokinetic parameters of OMD on days 1,3 , and 7 after dosing of OMDI ophthalmic solution $0.0025 \%$ in both eyes at 9:00 h. OMD was rapidly absorbed in both Japanese and Caucasian subjects; $C_{\max }$ was reached $\sim 10$ min after instillation.

After the peak concentration was reached, OMD concentration rapidly decreased in both Japanese and Caucasian subjects, with a mean $t_{1 / 2}$ of $\sim 30$ min. The mean plasma concentration decreased after $2 \mathrm{~h}$ to $\sim 2.0 \mathrm{pg} / \mathrm{mL}$ in Japanese subjects and $0.7 \mathrm{pg} / \mathrm{mL}$ in Caucasian subjects. All plasma concentration measurements, predose, and 4 and $8 \mathrm{~h}$ postdose, were below the limit of quantification $(<1.0 \mathrm{pg} / \mathrm{mL})$. A similar trend was observed for these measurements on days 3 and 7.

The mean \pm standard deviation (SD) $C_{\max }$ of OMD in each subject ranged from $37.5 \pm 15.5 \mathrm{pg} / \mathrm{mL}$ to $41.5 \pm 20.1 \mathrm{pg} / \mathrm{mL}$ in the Japanese subjects and from $27.2 \pm 10.2 \mathrm{pg} / \mathrm{mL}$ to $33.3 \pm 11.8 \mathrm{pg} / \mathrm{mL}$ in the Caucasian subjects throughout the treatment period. There was no accumulation of OMD plasma concentration after 7 days of repeated dosing once a day.

A retrospective statistical analysis found that after 7 days of administration, there were statistically significant differences in some of the pharmacokinetic parameters between Japanese and Caucasian subjects (Table 2). These differences became less prominent by days 3 and 7 and were not considered by the investigator(s) to be clinically or pharmacologically meaningful.

\section{Intraocular pressure}

The mean diurnal IOP \pm SD at baseline was $14.8 \pm$ $1.49 \mathrm{mmHg}$ for Japanese subjects and $15.1 \pm 1.84 \mathrm{mmHg}$ for Caucasian subjects. Following 7 days of dosing, the mean \pm SD diurnal IOP reduction was $4.92 \pm 1.37 \mathrm{mmHg}(33.2 \%)$ for the Japanese subjects and $5.41 \pm 1.67 \mathrm{mmHg}(35.8 \%)$ for the Caucasian subjects. The reduction in IOP was observed from $2 \mathrm{~h}$ after the dose (Fig. 2A). Maximum IOP reduction was achieved by day 3; this was sustained until the end of the study (Fig. 2A, B).

Table 1. Baseline Demographics and Clinical Characteristics

\begin{tabular}{lcrr}
\hline & Japanese $(\mathrm{n}=7)$ & Caucasian $(\mathrm{n}=7)$ & Overall $(\mathrm{n}=14)$ \\
\hline Mean age (SD), years & $29.6(4.6)$ & $29.9(3.2)$ & $29.7(3.8)$ \\
Male sex, $n(\%)$ & $7(100.0)$ & $7(100.0)$ & $14(100.0)$ \\
Iris color, $n(\%)$ & 0 & $1(14.3)$ & $1(7.1)$ \\
$\quad$ Blue/gray & 0 & $1(14.3)$ & $1(7.1)$ \\
Blue/gray/partially brown & 0 & $1(14.3)$ & $1(7.1)$ \\
Green & 0 & $3(42.9)$ & $3(21.4)$ \\
Green/partially brown & $7(100.0)$ & $1(14.3)$ & $8(57.1)$ \\
Brown & $14.79(1.49)$ & $15.10(1.84)$ & $14.94(1.62)$ \\
Mean diurnal IOP (SD), mmHg & $528.9(20.6)$ & $522.3(24.2)$ & $525.6(21.9)$ \\
Mean CCT (SD), $\mu \mathrm{m}$ & &
\end{tabular}

CCT, central corneal thickness; IOP, intraocular pressure; SD, standard deviation. 

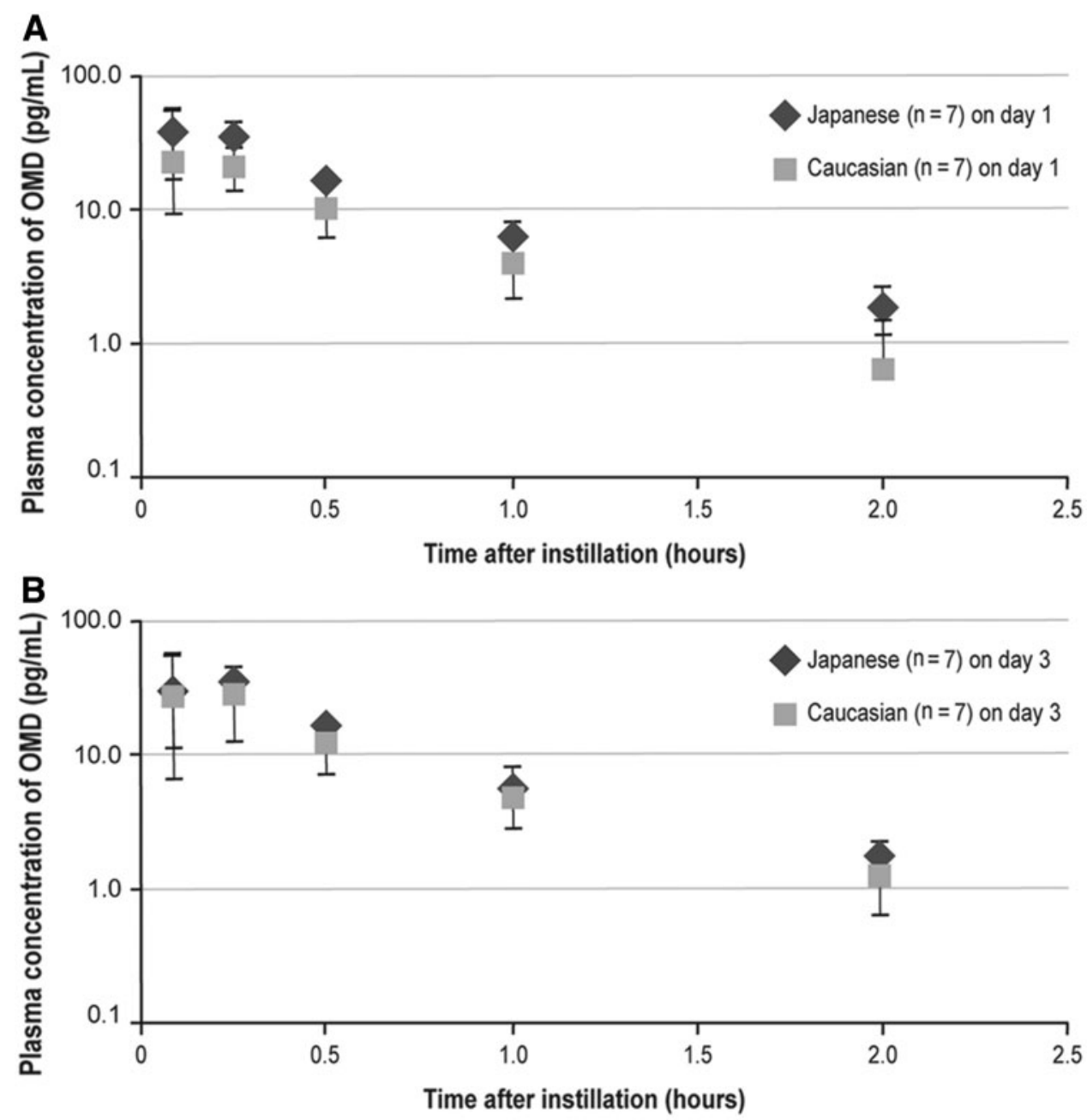

FIG. 1. Plasma concentration of OMD: mean \pm SD of concentration over time on (A) day 1, (B) day 3, and (C) day 7. OMD, omidenepag; SD, standard deviation.

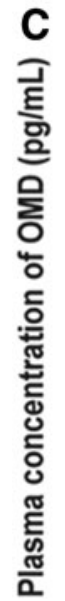

100.0

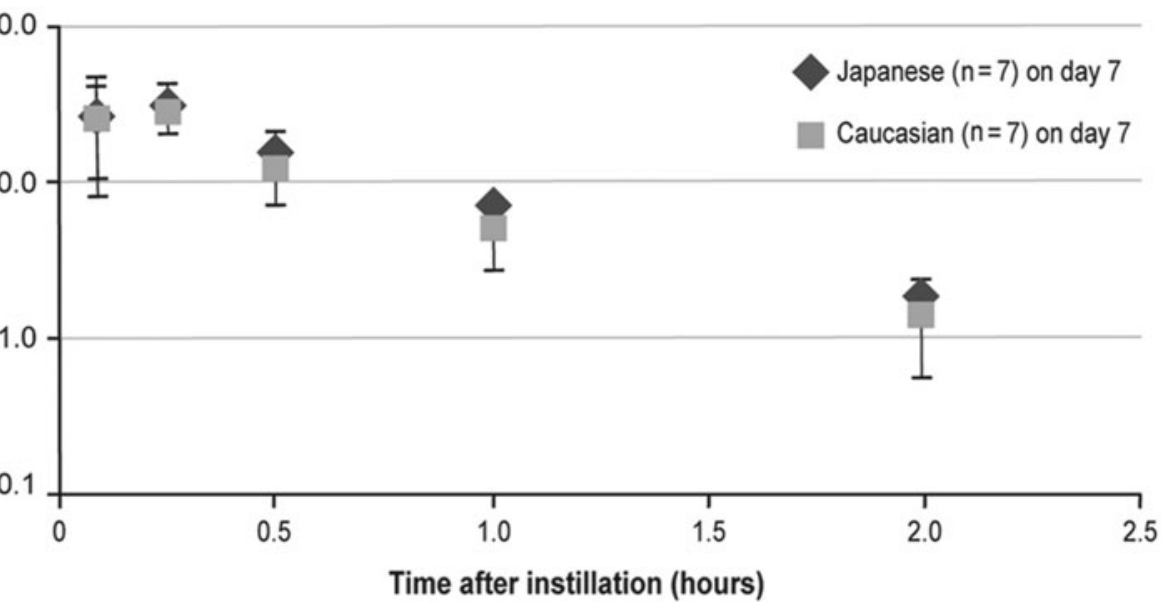

Safety

AEs and their severities are summarized in Table 3. There were no serious AEs reported and no discontinuations. All AEs were mild in severity and were judged by the investigator to be related to the study medication.

In the Japanese subject population, 1 subject experienced conjunctival hyperemia, increased AST, and increased ALT. In addition to the scheduled measurements of AST and ALT levels, unscheduled measurements were taken on day 16 for this sub- ject only. The increases in AST and ALT were of mild severity; there were no other sequelae or symptoms. AST levels increased from $20 \mathrm{IU} / \mathrm{L}$ at baseline to $40 \mathrm{IU} / \mathrm{L}$ on day 8 and decreased to $24 \mathrm{IU} / \mathrm{L}$ on day 16 during follow-up without intervention (reference range 13-33 IU/L). ALT levels were $33 \mathrm{IU} / \mathrm{L}$ at baseline, increased to $94 \mathrm{IU} / \mathrm{L}$ on day 8 , and returned to $40 \mathrm{IU} / \mathrm{L}$ on day 16 without intervention (reference range 8-42 IU/L). No other abnormal biochemistry values were reported as AEs.

In the Caucasian subject population, 3 subjects experienced AEs: 1 subject experienced both conjunctival 
Table 2. Pharmacokinetic Parameters of Omidenepag: Mean \pm Standard Deviation on Days 1,3 , and 7

\begin{tabular}{|c|c|c|c|c|c|}
\hline Analysis visit & Parameter & $\begin{array}{c}\text { Japanese }(\mathrm{n}=7) \\
\text { Mean }(S D)\end{array}$ & $\begin{array}{l}\text { Caucasian }(\mathrm{n}=7) \\
\quad \text { Mean }(S D)\end{array}$ & $\begin{array}{l}\text { Ratio of mean parameters } \\
\text { Japanese/Caucasian }\end{array}$ & $\begin{array}{c}t \text {-test } \\
P^{\mathrm{b}}\end{array}$ \\
\hline \multirow[t]{5}{*}{ Day 1} & $C_{\max }, \mathrm{pg} / \mathrm{mL}$ & $41.5(20.1)$ & $27.2(10.2)$ & 1.53 & 0.0203 \\
\hline & $T_{\max }, \mathrm{h}$ & $0.155(0.089)$ & $0.179(0.089)$ & 0.87 & 0.4683 \\
\hline & $t_{1 / 2}, \mathrm{~h}$ & $0.494(0.099)$ & $0.386^{\mathrm{c}}(0.162)$ & 1.28 & 0.0456 \\
\hline & $\mathrm{AUC}_{0-8 \mathrm{~h}}, \mathrm{~h} \cdot \mathrm{pg} / \mathrm{mL}$ & $26.1(5.7)$ & $15.3(4.7)$ & 1.71 & $<0.0001$ \\
\hline & $\mathrm{AUC}_{\mathrm{inf}}, \mathrm{h} \cdot \mathrm{pg} / \mathrm{mL}$ & $25.6(5.6)$ & $15.8^{\mathrm{c}}(4.7)$ & 1.62 & 0.0001 \\
\hline \multirow[t]{5}{*}{ Day 3} & $C_{\max }, \mathrm{pg} / \mathrm{mL}$ & $38.8(15.1)$ & $32.2(17.5)$ & 1.20 & 0.2781 \\
\hline & $T_{\max }, \mathrm{h}$ & $0.226(0.063)$ & $0.155(0.089)$ & 1.72 & 0.0170 \\
\hline & $t_{1 / 2}, \mathrm{~h}$ & $0.486(0.044)$ & $0.477(0.145)$ & 1.02 & 0.8088 \\
\hline & $\mathrm{AUC}_{0-8 \mathrm{~h}}, \mathrm{~h} \cdot \mathrm{pg} / \mathrm{mL}$ & $24.3(6.2)$ & $19.5(8.3)$ & 1.25 & 0.0803 \\
\hline & $\mathrm{AUC}_{\mathrm{inf}}, \mathrm{h} \cdot \mathrm{pg} / \mathrm{mL}$ & $23.8(6.1)$ & $19.1(8.1)$ & 1.25 & 0.0800 \\
\hline \multirow[t]{5}{*}{ Day 7} & $C_{\max }, \mathrm{pg} / \mathrm{mL}$ & $37.5(15.5)$ & $33.3(11.8)$ & 1.13 & 0.4078 \\
\hline & $T_{\max }, \mathrm{h}$ & $0.202(0.081)$ & $0.179(0.089)$ & 1.13 & 0.4490 \\
\hline & $t_{1 / 2}, \mathrm{~h}$ & $0.491(0.069)$ & $0.526^{\mathrm{d}}(0.095)$ & 0.93 & 0.2664 \\
\hline & $\mathrm{AUC}_{0-8 \mathrm{~h}}, \mathrm{~h} \cdot \mathrm{pg} / \mathrm{mL}$ & $25.0(6.6)$ & $19.8(4.8)$ & 1.26 & 0.0202 \\
\hline & $\mathrm{AUC}_{\mathrm{inf}}, \mathrm{h} \cdot \mathrm{pg} / \mathrm{mL}$ & $24.5(6.4)$ & $20.0^{\mathrm{d}}(4.8)$ & 1.23 & 0.0501 \\
\hline
\end{tabular}

${ }^{\mathrm{a}}$ Ratio of parameters generated from retrospective statistical analysis.

${ }^{\mathrm{b}} P$ value generated from retrospective statistical analysis for the difference in pharmacokinetic parameters between Japanese and Caucasian subjects.

${ }^{\mathrm{c}}$ Data represent the mean (SD) of 5 Caucasian subjects; insufficient data point for calculation for 2 Caucasian subjects.

${ }^{\mathrm{d}}$ Data represent the mean (SD) of 6 Caucasian subjects; insufficient data point for calculation for 1 Caucasian subject.

$\mathrm{AUC}_{0-8 \mathrm{~h}}$, area under the curve computed to $8 \mathrm{~h} ; \mathrm{AUC}_{\mathrm{inf}}$, AUC extrapolated to infinity; $C_{\max }$, maximum plasma concentration; $t_{1 / 2}$, halflife; $T_{\max }$, time to reach maximum plasma concentration.

hyperemia and photophobia, 1 subject experienced conjunctival hyperemia, and 1 experienced photophobia. In the 3 subjects in whom the AE of conjunctival hyperemia was reported, 2 AEs were observed from days 3-6 and the other from days 3-7. The conjunctival hyperemia presented intermittently. The frequency of bulbar conjunctival hyperemia by anterior segment photograph was higher immediately after OMDI dosing, then decreased, and resolved later in the day. When graded by the investigator(s) with biomicroscopy, none of the subjects had conjunctival hyperemia graded with an increase of $\geq 2 \mathrm{U}$.

Ocular AEs resolved without intervention within 4 days, and systemic AEs resolved without intervention within 8 days. There were no reported changes in vital signs, electrocardiograms, pachymetry, anterior chamber flare, or other AEs related to safety. CCT increased during OMDI treatment and remained stable from day 4 onward, with a maximum mean increase from baseline of $39.5 \pm 9.7 \mu \mathrm{m}$ $(7.5 \%)$ in Japanese subjects (day 5) and $36.4 \pm 21.3 \mu \mathrm{m}$ (7.0\%) in Caucasian subjects (day 4). CCT decreased once OMDI was discontinued; the change from baseline 1 day after discontinuation was $21.1 \pm 13.9 \mu \mathrm{m}(4.0 \%)$ in Japanese subjects (day 8) and $27.1 \pm 23.5 \mu \mathrm{m}(5.2 \%)$ in Caucasian subjects (day 8).

\section{Discussion}

This study demonstrated that repeated dosing of OMDI once a day led to low plasma levels of OMD that did not accumulate over time. $C_{\max }$ for all subjects was reached after $10-15 \mathrm{~min}$ and decreased with a $t_{1 / 2}$ of $\sim 30 \mathrm{~min}$. The AEs experienced by the subjects were all mild and resolved within 8 days, suggesting that OMDI was well tolerated. Topical application of OMDI resulted in mean IOP reductions of $33.2 \%$ and $35.8 \%$ in Japanese and Caucasian subjects, respectively. IOP reductions were sustained over $24 \mathrm{~h}$ following a single daily dose of OMDI. As a clinically significant IOP reduction is typically defined as $15 \%-20 \%$, this suggests that OMDI achieved clinically significant reductions in IOP. ${ }^{17}$

Variations in the pharmacokinetic properties of drugs between Asian and Caucasian subjects can occur because of differences in the functional and nonfunctional allelic variants of genes encoding enzymes that are involved in drug metabolism, such as CYP2C9, 2C19, and 2D6 subfamilies, or P450 cytochromes. ${ }^{18-20}$ These enzymes play an important role in metabolizing drugs. ${ }^{18} \mathrm{OMD}$ is metabolized by the CYP3A4 enzyme, a highly conserved enzyme that does not have a high degree of allelic variation, which limits the pharmacokinetic variation described for the aforementioned enzymes in different ethnicities. ${ }^{20}$ This makes it unlikely that there will be a difference in rates of OMD metabolism between these groups. ${ }^{20,21}$

After administration, there were statistically significant differences in some of the pharmacokinetic parameters between the Japanese and the Caucasian subjects in this study, particularly on day 1 . On days 1,3 , and 7, the Japanese/ Caucasian ratio for some of the pharmacokinetic parameters related to amount and concentration was $>1$ (Table $2 ; C_{\max }$, $\mathrm{AUC}_{0-8 \mathrm{~h}}$, and $\mathrm{AUC}_{\mathrm{inf}}$ ). This could be a consequence of the differences in mean body weight between the 2 populations, rather than being related to metabolic rate differences as a result of genetic variability. This study did not record weight data for subjects included in the analysis; however, the mean average body weight for Japanese males 26-39 years of age has been reported as $68.3 \mathrm{~kg}$, and the mean average body weight for Caucasian males 20-39 years of age was $87.9 \mathrm{~kg}^{22,23}$

In this study, based on the mean average body weights for these populations, the dose per weight was higher in Japanese subjects compared with Caucasian subjects: $\sim 0.022$ and $\sim 0.017 \mu \mathrm{g} / \mathrm{kg}$, respectively (Japanese/Caucasian dose 

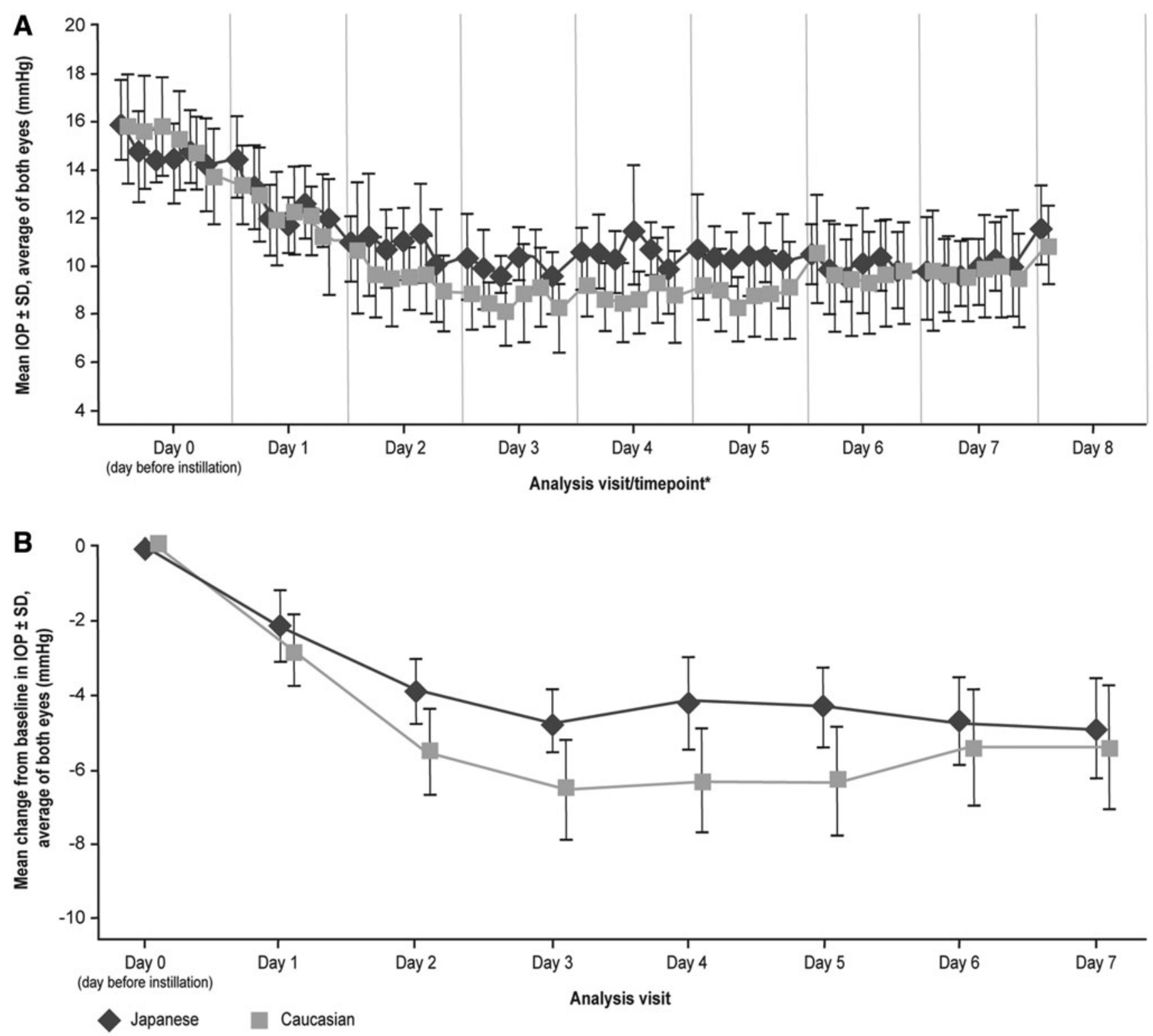

FIG. 2. (A) Mean \pm SD IOP at each time point, averaged over both eyes; (B) reduction in mean \pm SD diurnal IOP over time, averaged over both eyes. *IOP was measured during the screening period, 1 day before instillation (at 9:00, 10:00, 11:00, 13:00, 17:00, and 21:00 h), immediately before instillation $(9: 00 \mathrm{~h})$, at 1, 2, 4, 8, and 12 h postdose on days $1-7$, and at $9: 00 \mathrm{~h}$ on day 8 . IOP, intraocular pressure.

ratio: 1.29). That being said, this study was not designed to assess the statistical differences between the 2 patient populations. Therefore, the results of this ad hoc statistical analysis should be interpreted with caution.

Butaprost was one of the first EP2 agonists to be reported, but its clinical utility was limited because its structure was prone to undergoing dehydration, which made the drug inactive, and it had weak potency compared with endogenous prostaglandin E2. Therefore, it did not enter the clinical phases. $^{24}$

Another selective EP2 agonist, taprenepag isopropyl, was investigated in multiple animal models, which established that it was more potent than latanoprost $0.005 \%$ in terms of maximal IOP-lowering efficacy and 24-h IOP control. ${ }^{25}$ It was also demonstrated that a combination of taprenepag isopropyl and latanoprost exerted a greater IOP-lowering effect than either drug administered as monotherapy. How- ever, iritis was identified in a phase II study, occurring in $7.3 \%$ of patients over 14 days of treatment and $7.5 \%$ of patients over 28 days of treatment with taprenepag isopropyl monotherapy. ${ }^{25}$ The clinical development of taprenepag isopropyl has been discontinued.

OMDI remains the most potent EP2 agonist with regard to binding affinity for the EP2 receptor. ${ }^{24}$ No cases of iritis were reported with OMDI treatment during this phase I study, although this could be because of the small sample size and the short duration of treatment. A larger, longer trial would be needed to continue monitoring this AE.

Ocular AEs such as conjunctival hyperemia and photophobia are common side effects of current IOP-lowering medications, which occur as a result of the medication itself and the presence of tear-film-destabilizing preservatives. ${ }^{2,26-28}$ Conjunctival hyperemia and photophobia were observed in this study, but they were mild in severity and 
Table 3. Adverse Events and Severity

\begin{tabular}{lccc}
\hline $\begin{array}{l}\text { Subjects with any, } \\
\mathrm{n}(\%)\end{array}$ & $\begin{array}{c}\text { Japanese } \\
(\mathrm{n}=7)\end{array}$ & $\begin{array}{c}\text { Caucasian } \\
(\mathrm{n}=7)\end{array}$ & $\begin{array}{c}\text { Overall } \\
(\mathrm{n}=14)\end{array}$ \\
\hline AEs $^{\mathrm{a}}$ & $1(14.3)$ & $3(42.9)$ & $4(28.6)$ \\
Serious AEs & 0 & 0 & 0 \\
ADRs & $1(14.3)$ & $3(42.9)$ & $4(28.6)$ \\
Eye disorders & $1(14.3)$ & $3(42.9)$ & $4(28.6)$ \\
$\quad$ Conjunctival & $1(14.3)$ & $2(28.6)$ & $3(21.4)$ \\
$\quad$ hyperemia & $1(14.3)$ & $2(28.6)$ & $3(21.4)$ \\
$\quad$ Mild & 0 & $2(28.6)$ & $2(14.3)$ \\
Photophobia & 0 & $2(28.6)$ & $2(14.3)$ \\
$\quad$ Mild & $1(14.3)$ & 0 & $1(7.1)$ \\
Investigations & $1(14.3)$ & 0 & $1(7.1)$ \\
ALT increase & $1(14.3)$ & 0 & $1(7.1)$ \\
$\quad$ Mild & $1(14.3)$ & 0 & $1(7.1)$ \\
AST increase & $1(14.3)$ & 0 & $1(7.1)$ \\
$\quad$ Mild & 0 & 0 & 0 \\
Serious ADRs & 0 & 0 & 0 \\
Important risk (iritis) & 0 & 0 & 0 \\
AEs leading to study & 0 & & \\
discontinuation & & &
\end{tabular}

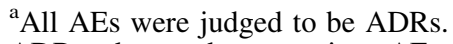

ADR, adverse drug reaction; AE, adverse event; ALT, alanine aminotransferase; AST, aspartate aminotransferase.

recovered during the study period. There were no reports of treatment termination due to AEs. Therefore, OMDI ophthalmic solution $0.0025 \%$ was considered tolerable in this study.

A slight increase in CCT of $7.5 \%$ and $7.0 \%$ was observed in Japanese and Caucasian subjects, respectively; this occurred after 5 days of OMDI dosing in Japanese subjects and after 4 days for Caucasian subjects. However, no AEs of corneal thickness were reported, and no corneal ede$\mathrm{ma} /$ swelling was observed with slit-lamp biomicroscopy. The extent of this increase is within physiological diurnal variation, which has previously been reported as $\sim 3 \%-$ $8 \% .{ }^{29}$ However, the data from the present study are limited by the small sample size. A study with a larger sample size and longer duration would be required to closely monitor this potential change in CCT and its associated impact on corneal health.

Other ocular hypotensives have also been shown to affect corneal thickness; for example, CAIs have been shown to increase CCT by $\sim 2 \%,,^{30,31}$ and FP agonists have been shown to decrease CCT by $\sim 2 \% .^{32,33}$ Several hypotheses have been proposed, including stromal swelling due to a CAI-mediated decrease in $\mathrm{HCO}_{3}{ }^{-30}$ or FP agonist-mediated upregulation of matrix metalloproteinases leading to decreased levels of collagen in the extracellular matrix of the corneal stroma. ${ }^{34,35}$ However, the precise mechanism by which OMDI increases CCT has yet to be elucidated, and further investigation is required.

The relatively short half-life of OMD in blood plasma indicates low systemic exposure with topical administration. The increase in liver enzyme levels (AST and ALT) reported in 1 Japanese subject was transient, did not result in any symptoms or sequelae, and recovered without intervention within 8 days after discontinuation of study medication. Therefore, it was not considered clinically significant. The peak AST level was 40 IU/L, a small elevation compared with the reference range of laboratory parameters for the study population (13-33 IU/L). Likewise, the peak ALT level in this study (94 IU/L; reference range 8-42 IU/L) showed only minimal elevation.

Increased AST and ALT levels may be caused by excessive exercise ${ }^{36,37}$ however, any subjects who had done or were planning to do excessive exercise during the study period from 7 days before OMDI instillation were excluded from the study. Increases in aminotransferase levels may also be caused by systemic infections. ${ }^{36}$ In summary, there appear to be no systemic safety concerns associated with topical use of OMDI ophthalmic solution $0.0025 \%$.

Topical application of OMDI resulted in clinically significant IOP reductions from $2 \mathrm{~h}$ after dosing, demonstrating an early onset of action. The maximum IOP-lowering effect was reached on day 3, after which IOP was stable for the duration of the treatment period. These findings suggest that OMDI could be used effectively with once-daily dosing and EP2 agonists could provide an option for efficacious glaucoma treatment in the future. An IOP reduction of $\sim 4.9-$ $5.4 \mathrm{mmHg}$ was achieved in healthy volunteers with normal IOP at study entry. This suggests that OMDI may be effective in lowering IOP in patients with normal-tension glaucoma; however, further studies will be required to confirm this hypothesis.

The limitations of this study are that only a limited number of participants were enrolled, the treatment was short term, and the study was not powered to assess statistical differences between the 2 patient populations. A relative strength of this study is the 2 distinct populations, allowing the data to be applied to a more diverse population.

In conclusion, when OMDI, a selective, nonprostaglandin, prostanoid EP2 agonist, was administered topically to healthy male volunteers, plasma levels of its active metabolite, OMD, were generally low with a short half-life. Accumulation after repeated dosing was not observed, indicating minimal systemic exposure, and there were no systemic safety concerns in this study. The pharmacokinetic parameters of OMD were similar in Japanese and Caucasian subjects after 7 days of repeated dosing, considering the difference in average body weights between the 2 cohorts.

Overall, OMDI ophthalmic solution $0.0025 \%$ had an acceptable tolerability profile. Topical treatment with OMDI resulted in clinically significant reductions in IOP. The maximum IOP-lowering effect was observed by day 3 , after which the IOP remained stable for the duration of the treatment term. The early onset of IOP reduction using a dosing regimen of once-daily drops provides the potential for good adherence to OMDI.

\section{Acknowledgments}

Medical writing was provided by Jennifer Mitchell, PhD, Helios Medical Communications, Cheshire, UK, which was funded by Santen.

\section{Author Disclosure Statement}

M.A. has received research support and honoraria/ consultation fees from Santen and has participated in a company-sponsored speaker's bureau for Santen. The following authors are all employees of Santen: Fenghe Lu, Hisashi Kawata, Yuki Tanaka, Kenzo Yamamura, Noriko Odani-Kawabata, and Naveed K. Shams. 


\section{Funding Information}

The study was sponsored by Santen.

\section{References}

1. Quigley, H., and Broman, A. Glaucoma. Lancet. 377:13671377, 2011.

2. Cheema, A., Chang, R.T., Shrivastava, A., and Singh, K. Update on the medical treatment of primary open-angle glaucoma. Asia Pac. J. Ophthalmol. (Phila.). 5:51-58, 2016.

3. Hoy, S.M. Netarsudil ophthalmic solution $0.02 \%$ : first global approval. Drugs. 78:389-396, 2018.

4. Kirihara, T., Taniguchi, T., Yamamura, K., et al. Pharmacologic characterization of omidenepag isopropyl, a novel selective EP2 receptor agonist, as an ocular hypotensive agent. Invest. Ophthalmol. Vis. Sci. 59:145-153, 2018.

5. Kass, M.A., Heuer, D.K., Higginbotham, E.J., et al. The ocular hypertension treatment study: a randomized trial determines that topical ocular hypotensive medication delays or prevents the onset of primary open-angle glaucoma. Arch. Ophthalmol. 120:701-713, 2002.

6. Schmier, J., Covert, D., and Hulme-Lowe, C. Adjunctive therapy patterns in glaucoma patients using prostaglandin analogs. Clin. Ophthalmol. 8:1097-1104, 2014.

7. Schmier, J.K., Lau, E.C., and Covert, D.W. Two-year treatment patterns and costs in glaucoma patients initiating treatment with prostaglandin analogs. Clin. Ophthalmol. 4: 1137-1143, 2010.

8. Ikeda, Y., Mori, K., Ishibashi, T., Naruse, S., Nakajima, N., and Kinoshita, S. Latanoprost nonresponders with openangle glaucoma in the Japanese population. Jpn. J. Ophthalmol. 50:153-157, 2006.

9. Rossetti, L., Gandolfi, S., Traverso, C., et al. An evaluation of the rate of nonresponders to latanoprost therapy. $J$. Glaucoma. 15:238-243, 2006.

10. Choplin, N., Bernstein, P., Batoosingh, A.L., Whitcup, S.M., and Bimatoprost/Latanoprost Study Group. A randomized, investigator-masked comparison of diurnal responder rates with bimatoprost and latanoprost in the lowering of intraocular pressure. Surv. Ophthalmol. 499(Suppl. 1):S19-S25, 2004.

11. Noecker, R.S., Dirks, M.S., Choplin, N.T., Bernstein, P., Batoosingh, A.L., and Whitcup, S.M. A six-month randomized clinical trial comparing the intraocular pressurelowering efficacy of bimatoprost and latanoprost in patients with ocular hypertension or glaucoma. Am. J. Ophthalmol. 135:55-63, 2003.

12. Fuwa, M., Toris, C., Fan, S., et al. Effects of a novel selective EP2 receptor agonist, omidenepag isopropyl, on aqueous humor dynamics in laser-induced ocular hypertensive monkeys. J. Ocul. Pharmacol. Ther. 34:531-537, 2018.

13. Toris, C.B., Zhan, G.-L., Camras, C.B., and McLaughlin, M.A. Effects of travoprost on aqueous humor dynamics in monkeys. J. Glaucoma. 14:70-73, 2005.

14. Toris, C.B., Gabelt, B.T., and Kaufman, P.L. Update on the mechanism of action of topical prostaglandins for intraocular pressure reduction. Surv. Ophthalmol. 53(Suppl. 1): S107-S120, 2008.

15. Serle, J.B., Podos, S.M., Kitazawa, Y., and Wang, R.F. A comparative study of latanoprost (Xalatan) and isopropyl unoprostone (Rescula) in normal and glaucomatous monkey eyes. Jpn. J. Ophthalmol. 42:95-100, 1998.
16. Aihara, M., Lu, F., Kawata, H., et al. Phase 2, randomized, dose-finding studies of omidenepag isopropyl, a selective EP2 agonist, in patients with primary open-angle glaucoma or ocular hypertension. J. Glaucoma. 28:375-385, 2019.

17. Noecker, R.J. The management of glaucoma and intraocular hypertension: current approaches and recent advances. Ther. Clin. Risk Manag. 2:193-206, 2006.

18. Kim, K., Johnson, J.A., and Derendorf, H. Differences in drug pharmacokinetics between East Asians and Caucasians and the role of genetic polymorphisms. J. Clin. Pharmacol. 44:1083-1105, 2004.

19. Bradford, L.D. CYP2D6 allele frequency in European Caucasians, Asians, Africans and their descendants. Pharmacogenomics. 3:229-243, 2002.

20. Zhou, Y., Ingelman-Sundberg, M., and Lauschke, V. Worldwide distribution of cytochrome P450 alleles: a meta-analysis of population-scale sequencing projects. Clin. Pharmacol. Ther. 102:688-700, 2017.

21. Werk, A.N., and Cascorbi, I. Functional gene variants of CYP3A4. Clin. Pharmacol. Ther. 96:340-348, 2014.

22. Ministry of Health, Labor and Welfare. National Health and Nutrition Survey Report. Part 2. Results of Physical Condition Survey. Japan: Ministry of Health, Labor and Welfare, 2013. Available at: https://www.mhlw.go.jp/ bunya/kenkou/eiyou/h25-houkoku.html Accessed June 11, 2019.

23. Fryar, C.D., Gu, Q., Ogden, C.L., and Flegal, K.M. Anthropometric reference data for children and adults: United States, 2011-2014. Vital Health Stat. 3. 2016, pp 1-46.

24. Markovič, T., Jakopin, Ž., Dolenc, M.S., and MlinaričRaščan, I. Structural features of subtype-selective EP receptor modulators. Drug Discov. Today. 22:57-71, 2017.

25. Schachar, R.A., Raber, S., Courtney, R., and Zhang, M. A Phase 2, randomized, dose-response trial of taprenepag isopropyl (PF-04217329) versus latanoprost $0.005 \%$ in open-angle glaucoma and ocular hypertension. Curr. Eye Res. 36:809-817, 2011.

26. Marquis, R.E., and Whitson, J.T. Management of glaucoma: focus on pharmacological therapy. Drugs Aging. 22:121, 2005.

27. Wong, T.T., Aung, T., and Ho, C.L. Ocular surface status in glaucoma and ocular hypertension patients with existing corneal disorders switched from latanoprost $0.005 \%$ to tafluprost $0.0015 \%$ : comparison of two prostaglandin analogues with different concentrations of benzalkonium chloride: latanoprost to tafluprost switching study. Clin. Exp. Ophthalmol. 46:1028-1034, 2018.

28. Pisella, P.J. Prevalence of ocular symptoms and signs with preserved and preservative free glaucoma medication. $\mathrm{Br}$. J. Ophthalmol. 86:418-423, 2002.

29. Feng, Y., Varikooty, J., and Simpson, T.L. Diurnal variation of corneal and corneal epithelial thickness measured using optical coherence tomography. Cornea. 20:480-483, 2001.

30. Kaminski, S., Hommer, A., Koyuncu, D., Biowski, R., Barisani, T., and Baumgartner, I. Influence of dorzolamide on corneal thickness, endothelial cell count and corneal sensibility. Acta Ophthalmol. Scand. 76:78-79, 1998.

31. Wilkerson, M., Cyrlin, M., Lippa, E.A., et al. Four-week safety and efficacy study of dorzolamide, a novel, active topical carbonic anhydrase inhibitor. Arch. Ophthalmol. 111:1343-1350, 1993.

32. Maruyama, Y., Mori, K., Ikeda, Y., Ueno, M., and Kinoshita, S. Effects of long-term topical prostaglandin therapy on 
central corneal thickness. J. Ocul. Pharmacol. Ther. 30:440_ 444, 2014.

33. Sen, E., Nalcacioglu, P., Yazici, A., et al. Comparison of the effects of latanoprost and bimatoprost on central corneal thickness. J. Glaucoma. 17:398-402, 2008.

34. Mehdizadeh, M., Jamshidian-Tehrani, M., and Nowroozzadeh, M.H. Corneal thickness and glaucoma medications. Ophthalmology. 116:1416-1417, 2009.

35. Sagara, T., Gaton, D.D., Lindsey, J.D., Gabelt, B.T., Kaufman, P.L., and Weinreb, R.N. Topical prostaglandin F2alpha treatment reduces collagen types I, III, and IV in the monkey uveoscleral outflow pathway. Arch. Ophthalmol. 117:794-801, 1999.

36. Giannini, E.G., Testa, R., and Savarino, V. Liver enzyme alteration: a guide for clinicians. CMAJ. 172:367-379, 2005.
37. Dufour, D.R., Lott, J.A., Nolte, F.S., Gretch, D.R., Koff, R.S., and Seeff, L.B. Diagnosis and monitoring of hepatic injury. I. Performance characteristics of laboratory tests. Clin. Chem. 46:2027-2049, 2000.

Received: April 8, 2019 Accepted: August 16, 2019

Address correspondence to: Dr. Fenghe Lu Santen, Inc. 6401 Hollis Street Emeryville, CA 94608

E-mail: Fenghe.Lu@santen.com 